\title{
Pedicle Screw Configuration for Thoracolumbar Burst Fracture Treatment: Short versus Long Posterior Fixation Constructs with and without Anterior Column Augmentation
}

\author{
Todd Peters ${ }^{1}$, Suresh Reddy Chinthakunta ${ }^{2}$, Mir Hussain ${ }^{2}$, Saif Khalil ${ }^{2}$ \\ ${ }^{1}$ One Brain and Spine Center, Newport Beach, CA, USA \\ ${ }^{2}$ Globus Medical Inc., Audubon, PA, USA
}

\begin{abstract}
Study Design: An in-vitro study.
Purpose: The current study is aimed at investigating the differences in stability between short posterior fixation (SPF), hybrid posterior fixation (HPF), and long posterior fixation (LPF) with and without anterior column augmentation using calcium phosphate bone cement (CaP) for treating burst fractures (BFs).

Overview of Literature: The ideal treatment for thoracolumbar BF is controversial regarding the use of short or LPF constructs.

Methods: Seven human thoracolumbar spines (T9-L4) were tested on a six degree of freedom spine simulator in three physiologic planes, flexion-extension (FE), lateral bending (LB), and axial rotation (AR). Tested surgical constructs included the following: intact, injury (BF), SPF (T12-L2), HPF (T11-L2), LPF (T11-L3), SPF+CaP, HPF+CaP, LPF+CaP, and CaP alone (CaP). Range of motion (ROM) was recorded at T12-L2 in FE, LB, and AR.

Results: The reduction in mean ROM trended as follows: LPF>HPF>SPF. Only LPF constructs and HPF with anterior column augmentation significantly reduced mean ROM in FE and LB compared to the intact state. All instrumented constructs (SPF, HPF, and LPF) significantly reduced ROM in FE and LB compared to the injured condition. Furthermore, the instrumented constructs did not provide significant rotational stability. Injecting CaP provided minimal additional stability.

Conclusions: For the injury created, LPF and HPF provided better stability than SPF with and without anterior column augmentation. Therefore, highly unstable fractures may require extended, long or hybrid fusion constructs for optimum stability.
\end{abstract}

Keywords: Spine; Fracture fixations; Bone screws; Bone cements

\section{Introduction}

The ideal treatment for thoracolumbar burst fractures (BFs) is controversial regarding the use of short or long posterior fixation constructs [1-4]. Long posterior fixa- tion (LPF) with pedicle screws and rods two-levels above and below the fracture level provide better fixation; however, it results in potentially extraneous instrumentation and increased load on the lower discs [5]. On the other hand, short posterior fixation (SPF) using pedicle screws

Received May 31, 2013; Revised Jul 12, 2013; Accepted Jul 14, 2013

Corresponding author: Suresh Reddy Chinthakunta

Globus Medical, Inc., 2560 General Armistead Ave, Audubon, PA 19403, USA

Tel: +1-610-930-1800, Fax: +1-610-930-2042, E-mail: sureshoubme@gmail.com 
with interconnected rods one-level above and below the fracture level not only limits the number of fused segments, but also prevents excessive loads on the adjacent discs. However, reports on the use of SPF for BFs describe high rates of failure in fixation and kyphotic collapse [2$4,6,7]$. Alternatively, pedicle screw constructs two-levels above and one-level below the fractured vertebra have been used clinically. This type of hybrid posterior fixation (HPF) increases the fixation while preserving one motion distally, and have shown to prevent progressive kyphosis [1]. More recently, there has been a renewed interest in limiting the number of motion segments fused by adding anterior column stabilization using transpedicular balloon vertebroplasty/ kyphoplasty using calcium phosphate cement $(\mathrm{CaP})$ or polymethylmethacrylate (PMMA) [2,8-11]. Studies on the reinforcement of SPF with PMMA or CaP have shown to restore anterior column vertebral height and kyphosis correction both biomechanically and clinically [8-11].

Previous investigators reporting the biomechanics of spinal instrumentation for thoracolumbar BFs have used different levels and species for testing the different methods of simulating $\mathrm{BF}$ or lacked a direct comparison of LPF, HPF and SPF with and without the addition of anterior column augmentation [1,2,11-15]. A few other studies have compared the use of adding an index level screw to SPF and LPF, but did not include HPF and also did not consider the effect of adding anterior column augmentation $[3,4,14,15]$. In the present study, the kinematic difference in the stability between these three treatment methodologies with and without anterior column augmentation using $\mathrm{CaP}$ bone cement is evaluated.

\section{Materials and Methods}

\section{Specimen preparation}

A total of 7 fresh frozen human cadaver spines (T10L4) were used in the study. The specimens were obtained from Science Care (Phoenix, AZ, USA) tissue bank. The medical history of each donor was examined to exclude trauma, malignancy or metabolic disease that might otherwise compromise the biomechanical properties of the lumbar spine. The specimens were harvested from two female and five male cadavers (mean age of death, $58 \pm 9$ years). Dual energy radiograph absorptiometry (QDRA010, Hologic Discovery, Waltham, MA, USA) was used to quantify the bone mineral density (BMD) (mean BMD, $0.8 \pm 0.1 \mathrm{~g} / \mathrm{cm}^{2}$ ). The specimens were radiographed in the anterioposterior and lateral planes in order to ensure the absence of fractures, deformities and any metastatic disease. The spines were dissected by carefully denuding the paravertebral musculature, avoiding the disruption of spinal ligaments, joints and disks. The spines were fixed at T10 proximally and L4 distally in a 2:1 mixture of Bondo auto body filler (Bondo Mar-Hyde Corp., Atlanta, GA, USA) and fiberglass resin (Home-Solution All Purpose, Bondo Mar-Hyde Corp.). Specimens were wrapped in saline-soaked $(0.9 \% \mathrm{NaCl})$ gauze to assure moist conditions during testing $[16,17]$. All tests were carried out at a room temperature of $25^{\circ} \mathrm{C}$.

\section{Multidirectional flexibility testing}

Each of the specimens was tested using a custom designed 6 degree of freedom (DOF) spine simulator (Fig. 1) configured with a motion analysis system (Optotrak Certus, NDI Inc., Waterloo, Canada) [17]. The 6 DOF apparatus is capable of applying pure, unconstrained rotational moments for the 3 axes, $\mathrm{X}, \mathrm{Y}$, and $\mathrm{Z}$. Unconstrained translations were permitted using air bearing guide rails ( $\mathrm{X}, \mathrm{Y}$, and $\mathrm{Z}$ ). The $\mathrm{L} 4$ vertebra of the spine was fixed to the load frame of a 6 DOF spine simulator and a pure moment was applied to the T10 vertebra via servomotors. Three infrared light-emitting diodes mounted non-collinearly on a plexiglass plate were rigidly attached to the anterior aspect of each vertebral body and served as points for motion measurement. Each of the test

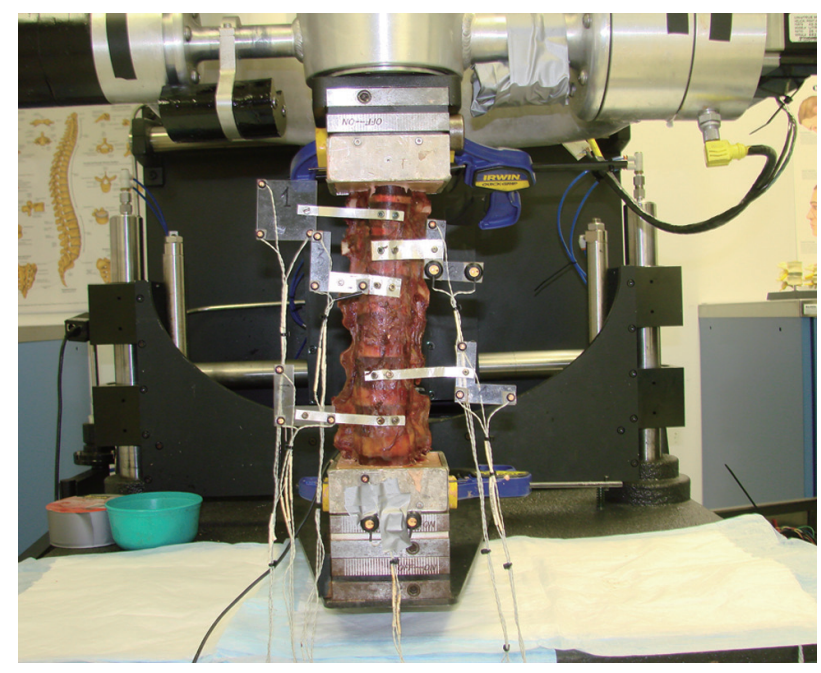

Fig. 1. Spine simulator setup. 
constructs was subjected to three load-unload cycles in each of the physiologic planes generating flexion-extension (FE), right-left lateral bending (LB) and right-left axial rotation (AR) load displacement curves. This was achieved by programming the motors to apply continuous moments in each physiologic plane. A typical loadunload cycle in the sagittal plane comprised of NeutralFull Flexion+Full Extension (2 times)-Neutral. Data from the third cycle were considered for analysis. The design of the load frame enabled unconstrained motion of the spine in response to an applied load. There was no compressive preload applied on the specimen. Flexibility testing using a load control protocol with $\pm 6 \mathrm{Nm}$ moments at a rate of $1 \% \mathrm{sec}$ was carried out for all other surgical constructs $[16,17]$. The three-dimensional intervertebral rotation was obtained from the motion analysis system data files in the form of Euler angles (degrees) for the $\mathrm{X}, \mathrm{Y}$, and $\mathrm{Z}$ axes, with $\mathrm{Rx} / \mathrm{Rx}, \mathrm{Rz} / \mathrm{-Rz}$ and $\mathrm{Ry} / \mathrm{-Ry}$ denoting FE, $\mathrm{LB}$, and $\mathrm{AR}$ range of motion (ROM), respectively [17].

\section{Burst fracture creation and stabilization}

In order to create a BF L1, minimal osteotomies were created at the anterior and lateral cortex of the $\mathrm{L} 1$ vertebral body in order to ensure a reproducible fracture at L1. Then, each vertebral body was compressed at $50 \mathrm{~mm} /$ min in a materials testing machine (MTS Bionix, Eden Prairie, MN, USA) [5]. Visual observation of the test
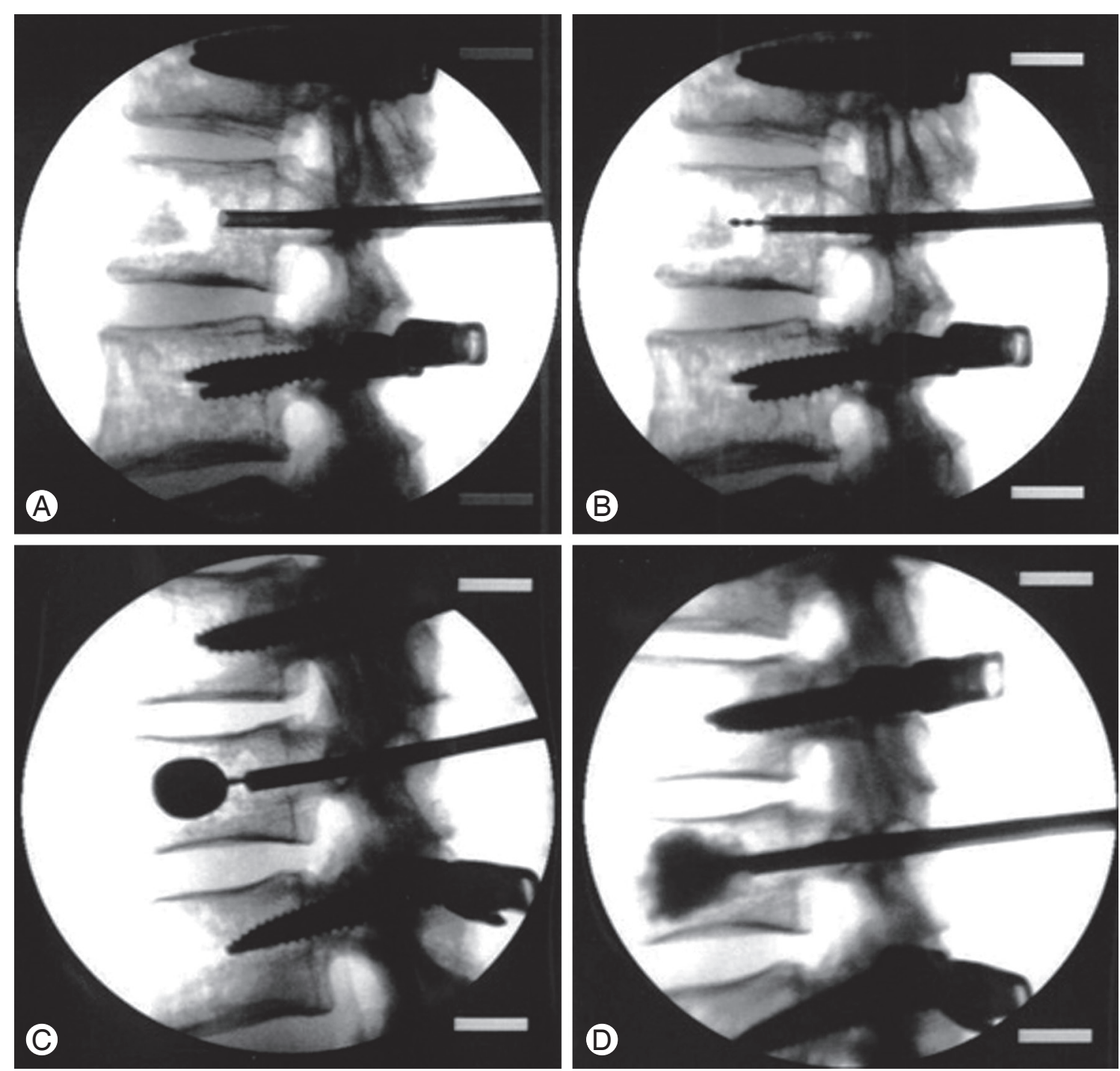

Fig. 2. Reinforcement using calcium phosphate cement. (A) Trocar inserted into both pedicles of the fractured vertebra. (B) Kyphoplasty balloons being carefully positioned. (C) Inserted kyphoplasty balloons being inflated under continous fluoroscopic monitoring. (D) Cement injection anteriorly into the fractured vertebra. 
was conducted to check for sudden changes in the loaddisplacement curves generated by the initiation of the BF. A sudden increase in flexibility indicated a BF. The axial load required to observe this sudden increase was on an average $1,000 \pm 500 \mathrm{~N}$. The procedure was repeated until disruption of the anterior and posterior walls of the vertebral body was seen on the lateral X-rays, confirming the creation of BF. In this study, the posterior elements were preserved thereby simulating a stable injury, as described by Holdsworth [18]. The fractures created in this study had $30 \%$ to $60 \%$ comminution of the body and $2 \mathrm{~mm}$ or greater displacement of fracture fragments in over $50 \%$ of the cross-sectional area, which corresponded to a 5-point score, according to McCormack et al's load sharing clas- sification scores [19].

\section{Stabilization of the fracture}

Stabilization of the fractured vertebral body was achieved using bilateral pedicle screw and rod constructs (REVERE Globus Medical Inc., Audubon, PA, USA) through LPF, HPF, and SPF. The L1 vertebral body was then reinforced with the calcium phosphate (CaP) bone cement (Kyphon Inc., Sunnyvale, CA, USA) through a balloon-assisted bilateral pedicular approach (Fig. 2) in combination with posterior instrumentation using LPF, HPF, and SPF.

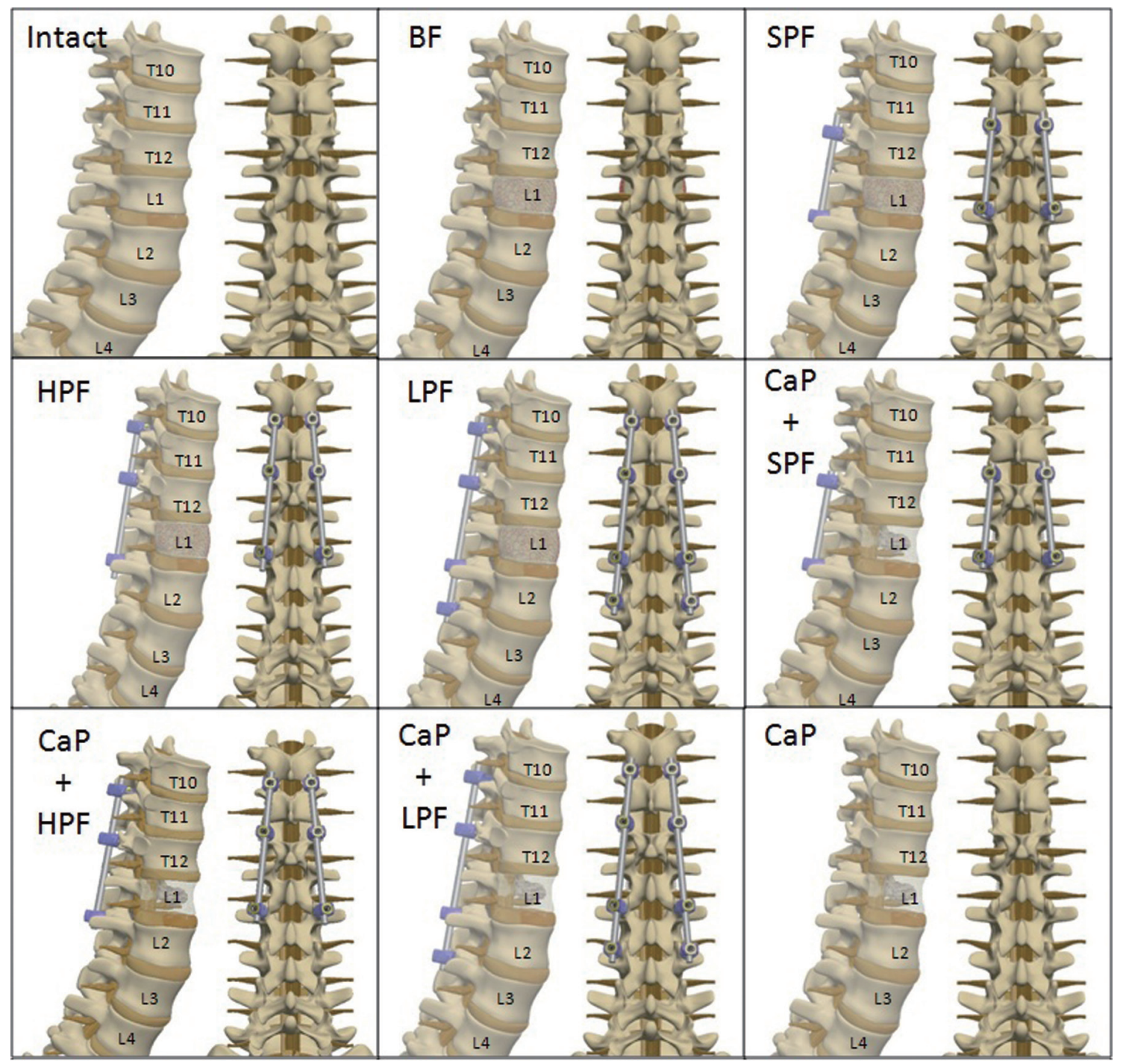

Fig. 3. Surgical constructs. BF, burst fracture; SPF, short posterior fixation; HPF, hybrid posterior fixation; LPF, long posterior fixation; CaP, calcium phosphate cement. 
Table 1. Mean range of motion and standard deviation (in degrees) at T10-L4 in flexion-extension, lateral bending, and axial rotation

\begin{tabular}{|c|c|c|c|}
\hline Surgical construct & Flexion-extension & Lateral bending & Axial rotation \\
\hline Intact & $6.19 \pm 0.61$ & $5.76 \pm 0.42$ & $2.43 \pm 1.29$ \\
\hline Injured & $12.03 \pm 3.21^{\text {a) }}$ & $10.89 \pm 2.38^{a)}$ & $4.2 \pm 1.37^{\mathrm{a})}$ \\
\hline SPF & $2.94 \pm 1.14^{\mathrm{b}, \mathrm{cl}}$ & $3.18 \pm 2.67^{b, c)}$ & $3.12 \pm 1.56^{c)}$ \\
\hline HPF & $2.26 \pm 1.78^{\mathrm{a}, \mathrm{b}, \mathrm{c})}$ & $2.2 \pm 3^{b, c)}$ & $2.83 \pm 1.15^{b, c)}$ \\
\hline LPF & $1.83 \pm 0.82^{a, b, c)}$ & $1.13 \pm 2.21^{a, b, c)}$ & $2.55 \pm 0.85^{b, c l}$ \\
\hline $\mathrm{SPF}+\mathrm{CaP}$ & $2.46 \pm 1.71^{a, b, c)}$ & $3.05 \pm 2.89^{b, c)}$ & $2.95 \pm 1.21^{b, c)}$ \\
\hline $\mathrm{HPF}+\mathrm{CaP}$ & $2.12 \pm 0.49^{a, b, c)}$ & $1.45 \pm 1.45^{\mathrm{a}, \mathrm{b}, \mathrm{c})}$ & $2.52 \pm 0.71^{b, c)}$ \\
\hline $\mathrm{LPF}+\mathrm{CaP}$ & $1.42 \pm 0.68^{a, b, c)}$ & $0.88 \pm 1.72^{a, b, c)}$ & $2.69 \pm 1.29^{b, c)}$ \\
\hline $\mathrm{CaP}$ & $10.54 \pm 2.51^{a, b, c)}$ & $10.79 \pm 2.27^{a, b, c)}$ & $4.49 \pm 1.41^{b, c)}$ \\
\hline
\end{tabular}

No significant differences among the instrumented constructs were observed, with and without anterior column augmentation. Significance was set at $p<0.05$.

SPF, short posterior fixation; HPF, hybrid posterior fixation; LPF, long posterior fixation; CaP, calcium phosphate cement.

${ }^{\text {a) }}$ Significant compared to the intact condition; ${ }^{b /}$ Sgnificant compared to the injured condition; ${ }^{\text {c) }}$ Significant compared to CaP only construct.

\section{Study design}

Each spine was tested for stability at T10-L4 in the intact condition in order to obtain the baseline values. Following intact testing, constructs were stabilized using SPF, HPF, and LPF for flexibility as follows: 1) BF and 2) augmentation using $\mathrm{CaP}$. Lastly, the $\mathrm{CaP}$ alone construct without any instrumentation was tested for stability. The test constructs are shown in the order they were tested in Fig. 3. In each tested condition, the specimens were subjected to pure moments of $\pm 6 \mathrm{Nm}$ in FE, $\mathrm{LB}$, and AR. The data was normalized to the intact condition (100\%).

\section{Data analysis}

Statistical analysis was performed on raw data using a repeated measures analysis of variance for independent samples, followed by Tukey's post-hoc analysis for multiple comparison procedures. Significance was set at $p<0.05$.

\section{Results}

All constructs were examined after testing, and none showed any visible signs of damage, loosening or breakage. The means and standard deviations for ROM in FE, LB, and AR are presented in Table 1 and Fig. 4.

\section{Flexion-extension}

The ROM was significantly reduced for all instrumented constructs compared to intact, injured and $\mathrm{CaP}$ conditions with LPF providing better stability compared to HPF and SPF; however, it was significant only when compared to SPF.

1) After injury

As expected, after injury, the ROM significantly increased by $21 \%$ compared to that of the intact condition. The SPF, HPF, and LPF constructs significantly improved construct stability by $35 \%, 53 \%$, and $65 \%$, respectively, compared to the injured condition. There was no significant difference in ROM between HPF and LPF constructs.

\section{2) After addition of $\mathrm{CaP}$}

Anterior column augmentation using $\mathrm{CaP}$ provided, on average, an additional stability of $6 \%$ (5\% over SPF, 3\% over HPF, and 9\% over LPF) over uncemented SPF, HPF, and LPF constructs. All the instrumented constructs SPF, HPF, and LPF significantly enhanced construct stability by $39 \%, 51 \%$, and $70 \%$ compared to the injured condition. CaP alone without posterior instrumentation did not provide significant stability compared to the intact and injured conditions.

\section{Lateral bending}

Similar to FE, ROM reduced significantly upon instru- 
mentation compared to the intact, injured and $\mathrm{CaP}$ conditions, and LPF provided improved stability over SPF and HPF. The injured and $\mathrm{CaP}$ constructs were the most unstable.

\section{1) After injury}

Following the BF creation, a $26 \%$ increase $(p<0.05)$ over intact ROM was observed. SPF, HPF, and LPF reduced motion by $36 \%, 54 \%$, and $68 \%$, respectively, compared to the injured condition.

\section{2) After addition of $\mathrm{CaP}$}

Reinforcement of SPF, HPF, and LPF using CaP enhanced construct stability by $6 \%, 3 \%$, and $9 \%$, respectively. After augmentation, using $\mathrm{CaP}, \mathrm{SPF}, \mathrm{HPF}$, and LPF reduced motion by $41 \%, 56 \%$, and $73 \%$, respectively, compared to the injured condition. CaP augmentation alone did not restore stability back to the intact condition.

\section{Axial rotation}

Unlike FE and LB, the instrumented constructs did not improve construct stability in AR. However, LPF provided better stability compared to SPF and HPF, similar to FE and LB.

1) After injury

Immediate to the BF, AR ROM significantly increased by $23 \%$ compared to the intact condition. All instrumented constructs reduced motion; yet, it was not significant compared to the intact condition. However, the reduction in motion (20\% after HPF and 30\% after LPF) was significant compared to the injured condition. There was no significant difference between LPF and HPF constructs.

\section{2) After addition of $\mathrm{CaP}$}

Even after the addition of $\mathrm{CaP}$, the motion did not significantly improve compared to the intact condition. Similar to the uncemented HPF and LPF constructs, the reduction in motion following augmentation using $\mathrm{CaP}$ was significant compared to the injured condition. However, $\mathrm{CaP}$ alone did not impart any stability.

\section{Discussion}

The common surgical goal of treatment in thoracolumbar fractures is obtaining the most stable fixation with fusion of the fewest segments possible. Both anterior

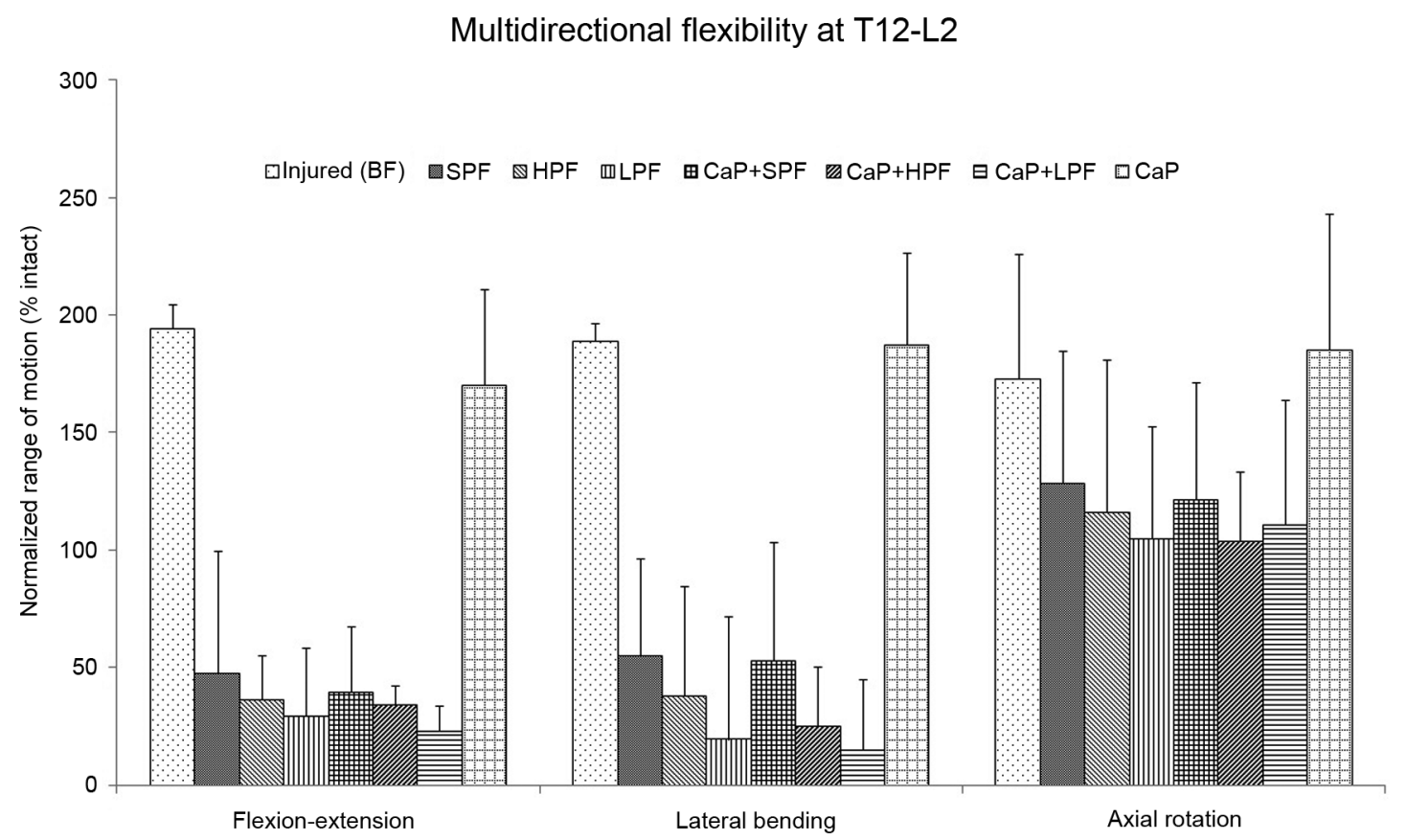

Fig. 4. Range of motion. BF, burst fracture; SPF, short posterior fixation; HPF, hybrid posterior fixation; LPF, long posterior fixation; CaP, calcium phosphate cement. 
and/or posterior approaches can be used, and the efficacy of either approach has been shown to be the same [20,21]. However, posterior approach is less extensive, and posterior fusion is the preferred choice of treatment for unstable thoracolumbar fractures [22,23]. Pedicle screw with interconnected rods allow immediate stable fixation as the screws traverse all the three columns. The main advantages of pedicle screw instrumentation over other forms of fixation (like wires and hooks) include the following: 1) correcting the deformities more effectively and 2) avoiding spinal canal encroachment $[1,3,4]$. In the present study, pedicle screws with interconnected rods posteriorly one-level above and below (short), twolevels above and below (long), and two-levels above and one-level below (hybrid) the fractured vertebra following $\mathrm{BF}$ creation were tested. The constructs were also tested following anterior column augmentation with calcium phosphate bone cement using the balloon-assisted bilateral pedicular approach. All instrumented constructs significantly improved stability of the BF segments beyond that of the intact state in FE and LB, but not in AR. Furthermore, following injury, only hybrid and LPF constructs reduced motion significantly compared to the injured condition in all loading modes.

At the thoracolumbar junction, previous authors have shown that the compressive forces act more anterior and therefore, require segmental transpedicular fixation two-levels above the fracture site in order to prevent progressive kyphosis and hardware failure [1,22]. de Peretti et al. [24] suggested that fixation by screw and hook constructs, gripping the two vertebrae above the lesion and screws and hooks gripping the first vertebra below the lesion were effective ways to stabilize thoracolumbar junction BFs. Carl et al. [22] also recommended using transpedicular segmental fixation two-levels above the fracture site. Tezeren and Kuru [12], in their study comparing short versus LPF constructs for thoracolumbar $\mathrm{BFs}$, demonstrated long instrumentation to be an effective way to manage thoracolumbar BFs. Gurr and McAfee [25] found that two-levels above and below (LPF) the injured level in an unstable calf spine model provided more stiffness than the intact spine. In the present study, hybrid and LPF posterior fixation significantly improved stability compared to intact and injured conditions in all loading modes. Furthermore, both fixations provided better stability compared to SPF. Therefore, LPF appears to be an effective way of managing thoracolumbar BFs. On the other hand, HPF can be used to preserve the motion segment as much as possible in the lumbar level.

In the present study, within the instrumented constructs stability offered trended as follows: $\mathrm{SPF}<\mathrm{HPF}<\mathrm{LPF}$. LPF was the stiffest of the 3 instrumented constructs with and without anterior column augmentation using $\mathrm{CaP}$ in all loading conditions, but was significantly stiffer when compared to SPF only. The use of screws two above and two below (LPF) has shown to not only enhance the stability but also allow effective reduction of kyphotic deformity $[1,2,12,14,15,22,24]$. However, SPF alone has also shown to provide good clinical and radiological outcomes for certain fractures, particularly in the more lordotic middle and lower lumbar spine, where the compressive forces act more posterior [1]. Katonis et al. [26] found that one-level above and one-level below (SPF) the fracture in the lumbar area formed a rigid construct with no correction loss. In the present study, the biomechanical performance of SPF significantly improved the stability beyond that of the intact and injured condition in FE.

The BF segments demonstrated the most instability in AR, even in the instrumented segments. Anterior column augmentation also did not restore the stiffness to the intact level in AR. These results are consistent with those of Slosar et al. [19] and Mann et al. [27], who discovered that posterior instrumentation increased stability beyond that of intact only in flexion and LB, while demonstrating that the surgical construct was less stable than the intact spine in AR. Chang et al. [13] also reported a similar observation in an L3 corpectomy model with a three-level transpedicular fixation system. Further, the experimental BFs in this study showed significantly more motion in all loading conditions. Panjabi et al. [28] and Willen et al. [29] found similar results for their experimental BFs. The results imply that any treatment of thoracolumbar BFs must be accommodated in order to reduce the acute instability of these injuries. It was further observed in this study that SPF constructs were significantly less stiff than hybrid and LPF constructs and was more pronounced in AR. Thus, additional instrumentation may be necessary for stiffness reconstruction, particularly when the posterior column is disrupted.

Previous studies have shown that the addition of $\mathrm{CaP}$ into the fractured vertebral body through a transpedicular approach to be a feasible technique $[9,10,30]$. It has also been hypothesized that this technique may improve outcomes in BF without the need for a secondary ante- 
rior approach [10]. CaP alone did not provide stability compared to the intact condition. However, additional instrumentation reduced motion significantly compared to the intact condition in FE and LB. Augmentation with $\mathrm{CaP}$ cement provided minimal additional stability compared to the conventional short, hybrid and LPF constructs. Furthermore, injury created by both hybrid and LPF without cement provided significantly better stability compared to SPF with cement. However, HPF with bone cement provided equivalent stability compared to LPF without the bone cement. Thus, HPF with anterior column augmentation using bone cement may be considered as an alternative to LPFs.

The present study does not take into account the structural stability provided by muscle forces and soft tissue. For such factors, the primary objective of this study is simply a trend comparison of different reconstruction techniques immediately postoperative. Moreover, because the data was normalized to the intact conditions, the findings of the study may not be affected by these natural variables. Lastly, the present study, similar to other in vitro biomechanical studies, may not account for all of the factors contributing to stability in vivo. Therefore, proper judgment is required when applying the results of these biomechanical studies to clinical situations. While clinical studies ultimately determine the success of these different reconstruction techniques, important insight into the relative stability of the reconstructed spine may be gained in vitro. Furthermore, the findings of this present study may help guide treating physicians into more comfortably selecting a suitable technique for safe stabilization in patients undergoing $\mathrm{BF}$ treatments.

\section{Conclusions}

In the burst fracture model, LPF and HPF provided better stability than SPF with and without anterior column augmentation. Therefore, highly unstable fractures may require extended, long fusion constructs for optimum stability. Hybrid posterior fixations may be considered as an alternative to LPF in order to avoid excessive load on the lower disc while increasing fixation.

\section{Conflict of Interest}

The authors acknowledge the funding for this project paid for by Globus Medical, Inc., which was conducted using machines and other equipment within their research department. Funding was provided in terms of staff salaries.

\section{Acknowledgments}

The authors would like to acknowledge Kelly Baker for conducting critical revisions to the manuscript.

\section{References}

1. Modi HN, Chung KJ, Seo IW, et al. Two levels above and one level below pedicle screw fixation for the treatment of unstable thoracolumbar fracture with partial or intact neurology. J Orthop Surg Res 2009;4:28.

2. Altay M, Ozkurt B, Aktekin CN, Ozturk AM, Dogan $\mathrm{O}$, Tabak AY. Treatment of unstable thoracolumbar junction burst fractures with short- or long-segment posterior fixation in magerl type a fractures. Eur Spine J 2007;16:1145-55.

3. Guven O, Kocaoglu B, Bezer M, Aydin N, Nalbantoglu $\mathrm{U}$. The use of screw at the fracture level in the treatment of thoracolumbar burst fractures. J Spinal Disord Tech 2009;22:417-21.

4. Mahar A, Kim C, Wedemeyer M, et al. Short-segment fixation of lumbar burst fractures using pedicle fixation at the level of the fracture. Spine (Phila Pa 1976) 2007;32:1503-7.

5. Tezeren G, Gumus C, Bulut O, Tukenmez M, Oztemur Z, Sever G. Anterior versus modified combined instrumentation for burst fractures of the thoracolumbar spine: a biomechanical study in calves. J Orthop Surg (Hong Kong) 2008;16:281-4.

6. McLain RF, Sparling E, Benson DR. Early failure of short-segment pedicle instrumentation for thoracolumbar fractures. A preliminary report. J Bone Joint Surg Am 1993;75:162-7.

7. Alanay A, Acaroglu E, Yazici M, Oznur A, Surat A. Short-segment pedicle instrumentation of thoracolumbar burst fractures: does transpedicular intracorporeal grafting prevent early failure? Spine (Phila $\mathrm{Pa}$ 1976) 2001;26:213-7.

8. Chen L, Yang H, Tang T. Unilateral versus bilateral balloon kyphoplasty for multilevel osteoporotic vertebral compression fractures: a prospective study. Spine (Phila Pa 1976) 2011;36:534-40. 
9. Khanna AJ, Lee S, Villarraga M, Gimbel J, Steffey D, Schwardt J. Biomechanical evaluation of kyphoplasty with calcium phosphate cement in a 2 -functional spinal unit vertebral compression fracture model. Spine J 2008;8:770-7.

10. Verlaan JJ, Dhert WJ, Verbout AJ, Oner FC. Balloon vertebroplasty in combination with pedicle screw instrumentation: a novel technique to treat thoracic and lumbar burst fractures. Spine (Phila Pa 1976) 2005;30:E73-9.

11. Cho DY, Lee WY, Sheu PC. Treatment of thoracolumbar burst fractures with polymethyl methacrylate vertebroplasty and short-segment pedicle screw fixation. Neurosurgery 2003;53:1354-60.

12. Tezeren G, Kuru I. Posterior fixation of thoracolumbar burst fracture: short-segment pedicle fixation versus long-segment instrumentation. J Spinal Disord Tech 2005;18:485-8.

13. Chang KW, Dewei Z, McAfee PC, Warden KE, Farey ID, Gurr KR. A comparative biomechanical study of spinal fixation using the combination spinal rodplate and transpedicular screw fixation system. J Spinal Disord 1988;1:257-66.

14. Baaj AA, Reyes PM, Yaqoobi AS, et al. Biomechanical advantage of the index-level pedicle screw in unstable thoracolumbar junction fractures. J Neurosurg Spine 2011;14:192-7.

15. Lazaro BC, Deniz FE, Brasiliense LB, et al. Biomechanics of thoracic short versus long fixation after 3-column injury. J Neurosurg Spine 2011;14:226-34.

16. Wilke HJ, Wenger K, Claes L. Testing criteria for spinal implants: recommendations for the standardization of in vitro stability testing of spinal implants. Eur Spine J 1998;7:148-54.

17. Mindea SA, Chinthakunta S, Moldavsky M, Gudipally M, Khalil S. Biomechanical comparison of spinopelvic reconstruction techniques in the setting of total sacrectomy. Spine (Phila Pa 1976) 2012;37:E16227.

18. Holdsworth F. Fractures, dislocations, and fracturedislocations of the spine. J Bone Joint Surg Am 1970;52:1534-51.

19. Slosar PJ Jr, Patwardhan AG, Lorenz M, Havey R, Sartori M. Instability of the lumbar burst fracture and limitations of transpedicular instrumentation. Spine (Phila Pa 1976) 1995;20:1452-61.
20. Danisa OA, Shaffrey CI, Jane JA, et al. Surgical approaches for the correction of unstable thoracolumbar burst fractures: a retrospective analysis of treatment outcomes. J Neurosurg 1995;83:977-83.

21. Kaneda K, Taneichi H, Abumi K, Hashimoto T, Satoh S, Fujiya M. Anterior decompression and stabilization with the Kaneda device for thoracolumbar burst fractures associated with neurological deficits. J Bone Joint Surg Am 1997;79:69-83.

22. Carl AL, Tromanhauser SG, Roger DJ. Pedicle screw instrumentation for thoracolumbar burst fractures and fracture-dislocations. Spine (Phila Pa 1976) 1992;17(8 Suppl):S317-24.

23. Roy-Camille R, Saillant G, Mazel C. Internal fixation of the lumbar spine with pedicle screw plating. Clin Orthop Relat Res 1986;(203):7-17.

24. de Peretti F, Hovorka I, Cambas PM, Nasr JM, Argenson $\mathrm{C}$. Short device fixation and early mobilization for burst fractures of the thoracolumbar junction. Eur Spine J 1996;5:112-20.

25. Gurr KR, McAfee PC. Cotrel-Dubousset instrumentation in adults. A preliminary report. Spine (Phila Pa 1976) 1988;13:510-20.

26. Katonis PG, Kontakis GM, Loupasis GA, Aligizakis AC, Christoforakis JI, Velivassakis EG. Treatment of unstable thoracolumbar and lumbar spine injuries using Cotrel-Dubousset instrumentation. Spine (Phila Pa 1976) 1999;24:2352-7.

27. Mann KA, McGowan DP, Fredrickson BE, Falahee $M$, Yuan HA. A biomechanical investigation of short segment spinal fixation for burst fractures with varying degrees of posterior disruption. Spine (Phila $\mathrm{Pa}$ 1976) $1990 ; 15: 470-8$.

28. Panjabi MM, Oxland TR, Lin RM, McGowen TW. Thoracolumbar burst fracture. A biomechanical investigation of its multidirectional flexibility. Spine (Phila Pa 1976) 1994;19:578-85.

29. Willen J, Lindahl S, Irstam L, Aldman B, Nordwall A. The thoracolumbar crush fracture. An experimental study on instant axial dynamic loading: the resulting fracture type and its stability. Spine (Phila Pa 1976) 1984;9:624-31.

30. Mermelstein LE, McLain RF, Yerby SA. Reinforcement of thoracolumbar burst fractures with calcium phosphate cement. A biomechanical study. Spine (Phila Pa 1976) 1998;23:664-70. 